\title{
REE fluorocarbonate synthesis via reactions with carbonate wall rock
}

\author{
DYLAN PRICE, IAN BUTLER, BRYNE NGWENYA AND \\ LINDA KIRSTEIN
}

University of Edinburgh

Presenting Author: dylan.price@ed.ac.uk

The formation of REE (fluoro)carbonates in hydrothermal systems is principally governed by the chemistry of REE complexes in hydrothermal solutions and the reactions of dissolved species with wall rocks that are conduits for those fluids [1]. This interaction has been quantified both experimentally [2] and from a modelling approach for specific REEs [1].

As natural hydrothermal fluids transport an assemblage of REEs, our experiments focusses on the influence of both discrete and mixed REEs during reactions of hydrothermal fluids with wall rocks to produce REE bearing minerals. The influence of multiple, mixed REE is a factor that has not been extensively studied [3].

We synthesised REE (fluoro)carbonates by reacting discrete and mixed REE chloride starting solutions with a mixed dolomitic carbonate and fluorite pellet "wall-rock" from $90^{\circ} \mathrm{C}$ to $200^{\circ} \mathrm{C}$. Fluorite is an experimentally practical means of overcoming the low solubility of REE fluorides at low temperatures. The resulting material was analysed by XRD and SEM/EDS to identify mineral phases and their REE distribution.

Initial results of mixed REE experiments shows the formation of the fluorocarbonate mineral bastnäsite. This is particularly noteworthy for the mixtures with La combined with a heavier REE such as Er or Yb. Samples with only a single element of Er or $\mathrm{Yb}$ did not yield bastnäsite, which is consistent with the mineral's occurrence in natural systems. For the discrete REEs, bastnäsite occurs from a $\mathrm{La}$ and $\mathrm{Nd}$ starting solution. At lower temperatures, $\mathrm{Yb}$ results in a $\mathrm{Yb}$ fluoride and $\mathrm{Er}$ yields a tengerite structure. At elevated temperatures, discrete $\mathrm{Er}$ and $\mathrm{Yb}$ experiments do not result in common REE minerals. In investigating the behavior of REE during wall rock reactions, it is essential to use mixtures of REEs in addition to discrete REE.

[1] Migdisov et al. (2016). Chemical Geology, 439, pp.13-42.

[2] Szucs et al. (2020). Crystal Growth \& Design, 21, 1, pp.512-527.

[3] Holloway, M. (2017). PhD Thesis, University of Edinburgh. 